\title{
CULTURA, CULTURA POLÍTICA E PARTICIPAÇÃO POLÍTICA: CONCEITOS E CONCEPÇÕES NO DEBATE SOBRE OS MOVIMENTOS SOCIAIS ARGENTINOS Pós-2001
}

Camila Penna

\begin{abstract}
Resumo
A proposta do trabalho é sugerir um diálogo entre alguns conceitos correntemente utilizados na análise dos movimentos sociais e da participação política na América Latina, quais sejam: projetos políticos, cultura política, hibridismo e frames ou enquadramento. Para tanto, discutimos à luz do debate teórico sobre cultura política e democracia na América Latina, três movimentos sociais surgidos na Argentina no final da década de 90 e início do século XXI. A partir da discussão de algumas características destes movimentos sociais argumenta-se que eles representaram, em certa medida, inovações para o significado de participação política e de democracia; inovações essas que permitem um questionamento do que tem sido classificado, pela literatura, como cultura política tradicional da América Latina.
\end{abstract}

Palavras-chave: Movimentos Sociais; Argentina; Cultura Política; América Latina; Democracia.

\begin{abstract}
The article aims at suggesting a dialogue between some theoretical concepts often used on Latin-American political participation and social movement literature, namely: political project, political culture, hybridism and frame. Taking into account the theoretical debate on political culture and democracy in Latin America we analyze three social movements emerged in Argentine in the 90's and the beginning of the XXI Century. After discussing some of the characteristics of these social movements we argue that such movements represent an innovation to the meaning of political participation and democracy and that this innovation allows us to question, to some extent, what has been generally treated by the literature as the Latin-American traditional political culture.
\end{abstract}

Key-words: Social Movements; Argentina; Political Culture; Latin-America; Democracy.

\section{Introdução}

O artigo faz uma revisão da literatura sobre cultura política, democracia participativa e movimentos sociais, discutindo, a partir deste debate, alguns dos movimentos sociais surgidos na Argentina ao longo da década de 1990: os movimentos dos trabalhadores de empresas 
recuperadas, de desempregados e as assembléias de bairro ${ }^{1}$. Objetiva-se apreender o significado destes movimentos dentro do contexto político argentino e, de forma mais ampla, latino-americano, partindo-se das categorias e conceitos presentes na literatura referida. A partir desta discussão nos propomos a analisar em que medida as formas de ação coletiva e os processos de produção simbólica levados a cabo por esses movimentos resultaram em uma mudança cultural, ou em uma ruptura com alguns dos elementos apontados pela literatura como típicos de uma cultura política característica da América Latina.

Em um primeiro momento abordaremos a literatura sobre cultura política e cultura, de modo mais amplo, buscando construir uma estrutura analítica que nos permita avaliar os movimentos sociais a partir da perspectiva proposta. Nesse sentido, discutiremos também algumas abordagens teóricas sobre movimentos sociais, enfocando seu diálogo com a primeira literatura.

Após discussão teórica sobre cultura política e movimentos sociais passaremos a uma revisão dos trabalhos que discutem cultura política e democracia na América Latina; o que nos fornecerá um contexto histórico e político para o tratamento da questão argentina. No tópico seguinte iremos discutir o contexto de crise argentina - política e econômica -, no qual surgiram os movimentos, e apresentar algumas de suas características, mais especificamente as que se referem aos objetivos, modos de ação, e estruturas cognitivas características destes movimentos.

Por fim, trataremos de analisar o significado destes movimentos, e do que eles produziram em termos simbólicos e materiais, para a visão do que seria uma cultura política dominante na América Latina - considerandose não apenas a bibliografia sobre cultura política, mas permeando-a e

\footnotetext{
${ }^{1}$ As assembléias de bairro já existiam antes de 2001 e representam uma tradição de longa data na Argentina, as primeiras foram formadas ainda no século XIX (GONZÁLEZ et al, 1985). O que se verificou a partir de 2001 foi a intensificação de suas atividades e uma participação massiva nas assembléias que já existiam bem como o surgimento de novas assembléias.
}

REVISTA DEBATES, Porto Alegre, v. 2, n. 2, p. 70-102, jul.-dez. 2008. 71 
propondo um diálogo com categorias e conceitos presentes na literatura mais ampla sobre movimentos sociais e participação política.

\section{Cultura política e cultura como categorias analíticas}

O campo de estudos sobre a cultura política teve como um dos seus expoentes o trabalho de Gabriel Almond e Sidney Verba, The Civic Culture (1963). Nele os autores definem cultura política como "orientações especificamente políticas - atitudes em relação ao sistema político e suas várias partes, e atitudes em relação ao papel do self no sistema" (ALMOND e VERBA, 1963, p. 12). Sobre a utilidade do termo cultura, os autores argumentam que seu uso os permitiria utilizar conceitos e abordagens da antropologia, sociologia e psicologia. Contudo, para evitar ambigüidades dos diversos usos do conceito nestes campos, os autores limitam o emprego do termo a: orientações psicológicas em relação a objetos sociais. Orientações entendidas aqui como "aspectos internalizados de objetos e relações" (ALMOND e VERBA, 1963, p. 13-14). A cultura política de uma sociedade se refere, pois, ao "sistema político como internalizado nas cognições, sentimentos, e avaliações da população" (ALMOND e VERBA, 1963, p. 13).

A partir destas definições, podemos observar que a concepção de cultura política de Almond e Verba se preocupa em explicar as orientações dos indivíduos - entendidos de forma individualizada e não coletiva acerca do sistema político formal. Mesmo quando se referem às orientações dos indivíduos em relação ao self como ator político, eles consideram apenas suas orientações em relação ao "conteúdo e qualidade das normas de obrigação política pessoal e conteúdo e qualidade do senso de competência pessoal vis-à-vis o sistema político" (ALMOND e VERBA, 1963, p. 14). Não há, nesse sentido, preocupação em explicar as cognições e ações dos indivíduos em relação à política em um sentido mais amplo, fora do sistema político formal. Importa observar também que para Almond e Verba o modelo de cultura política seria a cultura cívica, presente apenas

REVISTA DEBATES, Porto Alegre, v. 2, n. 2, p. 70-102, jul.-dez. 2008.72 
nos Estados Unidos e Inglaterra (dentre os cinco países estudados), a qual, por sua vez, seria a base de sustentação da democracia nesses países. Portanto, para que um sistema democrático - entendido aqui em termos de um modelo liberal - pudesse funcionar efetivamente em nações nascentes e em outros países em desenvolvimento, seria necessário o desenvolvimento de uma cultura política democrática (cultura cívica).

Essa concepção de que o fim político desejável para os países em desenvolvimento seria o estabelecimento de uma democracia nos moldes da norte-americana e inglesa, e de que uma cultura política correspondente deveria ser desenvolvida para tanto, rendeu a Almond e Verba algumas acusações de etnocentrismo. O trabalho foi criticado, ademais, por conceber cultura política como uma categoria redutível a concepções individuais e particulares de cada pessoa (AVRITZER, 2002), limitada a orientações atomísticas. Com efeito, a cultura política de uma nação é entendida como o conjunto, agregado, destas orientações individuais (ALMOND e VERBA, 1963).

A concepção de cultura política de Almond e Verba é problematizada por diversos autores. Ao passo que alguns questionam sua aplicabilidade para a realidade latino-americana - que apresenta contextos sócio-políticos e culturais distintos (BAQUERO, 2001, 1994; CASTRO, 1998) outros autores a rejeitam por completo e propõem uma nova definição (AVRITZER, 2002). A crítica de Avrizter à concepção de cultura política de Almond e Verba se refere ao fato de que estes a entendiam como "uma categoria que pertence ao interior da mente" (AVRITZER, 2002, p. 58), e que, em contrapartida, as teorias culturais recentes estariam apontando para o fato de que a cultura pertence à esfera das práticas sociais. O autor propõe então uma visão de cultura como tendo uma dimensão coletiva - na medida em que envolve um conjunto de práticas compartilhado por uma porção ou toda a sociedade 
-; e uma dimensão pública, uma vez que se expressa em relações ativas entre grupos e que tomam lugar no nível público².

Nesse sentido, Avritzer conceitua cultura política da seguinte forma: "disputa pública sobre o significado de práticas políticas que irão determinar novos comportamentos institucionais na política" (AVRITZER, 2002, p. 58). Em consonância com Almond e Verba ele entende que cada sociedade tem uma cultura política dominante ${ }^{3}$. Mas que também estão presentes tentativas de desafiar essa cultura política dominante através de ações no nível público.

Noção similar de disputa e de tentativas de suplantar a cultura política dominante - através de ações na esfera pública - por uma mais participativa e igualitária, também está presente em Dagnino (2004, 2006). Ela introduz o conceito de projetos políticos, em torno dos quais estaria se configurando uma disputa simbólica sobre diferentes significados e concepções de cidadania, sociedade civil e participação na América Latina. Embora para Dagnino o significado de projeto político não seja equivalente ao de cultura política (ou tradição política), os projetos políticos seriam constituídos no contexto e a partir de determinada cultura política - a qual eles poderiam, não obstante, alterar em alguma medida.

Projetos políticos se referem a "conjuntos de crenças, interesses, concepções de mundo, representações do que deve ser a vida em

\footnotetext{
${ }^{2}$ Convém observar que aqui há referência a dois conceitos distintos: cultura política e cultura. Como veremos adiante, alguns autores utilizam esses termos de forma intercambiável (BRIONES, ROSAN e FAVA, 2004); outros falam apenas de cultura para se referir a cognições e concepções dos indivíduos acerca de política e ação política (GRISMSON, 2004); e outros trabalham com a concepção de projetos políticos e frames (DAGNINO, 2006; DELLA PORTA e DIANI, 1999), cuja definição, como veremos, se aproxima da idéia de cultura, em um sentido mais amplo, mas também parece estar contida nela. A cultura política será entendida, para os propósitos deste trabalho, como parte de um conceito mais abrangente, qual seja, o de cultura. Com efeito, acreditamos que a apreensão da cultura política como uma dimensão da cultura - dimensão que se refere ao conjunto de normas, crenças, concepções simbólicas e valores relativos à política - é importante para compreender e explicar alguns fenômenos que transcendem a relação dos indivíduos com o sistema político, como, por exemplo, as motivações para a ação coletiva, a produção simbólica, a internalização de diferentes visões de mundo, e a influência do imaginário coletivo nas práticas e valores dos indivíduos.

${ }^{3}$ A idéia do que seria essa cultura política dominante na América Latina para diversos autores será discutida no próximo tópico.
}

REVISTA DEBATES, Porto Alegre, v. 2, n. 2, p. 70-102, jul.-dez. 2008.74 
sociedade, que orientam a ação política dos diferentes sujeitos" (DAGNINO, 2006, p. 38). Na noção de projeto político estaria implícita, segundo a autora, uma idéia de intencionalidade e do papel do sujeito como agência, bem como a afirmação da política como terreno estruturado por escolhas, expressas nas ações e orientadas por estruturas cognitivas dos indivíduos. Nesse sentido, Dagnino aponta que a noção de projeto político não se reduz a estratégias de atuação política no sentido estrito ou a formulações sistematizadas e abrangentes como os projetos partidários, mas "expressam, veiculam e produzem significados que integram matrizes culturais mais amplas" (DAGNINO, 2006, p. 39-40). Projetos políticos contêm, ademais, visões acerca do que deve ser a vida em sociedade e servem de orientação para ação política. Contudo, não são homogêneos, possuindo várias combinações em seu interior - que não estão limitadas a relações de classe.

Feitas essas ressalvas, Dagnino identifica três grandes projetos presentes na América Latina: autoritário, neoliberal e democráticoparticipativo. O autoritário - embora ainda permaneçam elementos característicos deste projeto na sociedade latino-americana - não tem, atualmente, a centralidade dos dois outros projetos, em torno dos quais se configura a disputa pela construção democrática. Com efeito, a disputa que se trava atualmente na América Latina seria uma disputa - entre o projeto neoliberal e o democrático-participativo - por produção simbólica de significados para noções como democracia, cidadania, participação e sociedade civil. Seria, pois, um conflito principalmente discursivo, cujo vencedor seria aquele que conseguisse a hegemonia sobre significados, interpretações e visões de mundo favoráveis a seu projeto político - uma vez que a estrutura cognitiva hegemônica, ao ser internalizada pelos indivíduos, orientaria determinado tipo de ação política ${ }^{4}$.

\footnotetext{
${ }^{4}$ Alguns dos conceitos em disputa pelos projetos neoliberal e democrático participativo seriam os de cidadania, sociedade civil, participação, democracia e política. De acordo com Dagnino (2004, 2006), no projeto político neoliberal o significado de cidadania teria se deslocado de uma noção de cidadania ampliada, de direito a ter direitos e criação de novos direitos para os excluídos, para uma cidadania relacionada à idéia de solidariedade para com os pobres, ou
}

REVISTA DEBATES, Porto Alegre, v. 2, n. 2, p. 70-102, jul.-dez. 2008. 75 
A disputa no contexto latino-americano seria caracterizada, pois, por um deslocamento de significados que teve origem e foi, em grande medida, o resultado da implementação do projeto político neoliberal por alguns países na década de 90. Com a dissipação das idéias neoliberais, as noções de cidadania, participação, e sociedade civil, tão caras à democracia, estariam perdendo os significados que haviam sido construídos no contexto das transições democráticas - contexto em que o projeto democráticoparticipativo havia amadurecido e ganhado espaço, assim como os sentidos e visões de política e democracia por ele forjados (DAGNINO, 2004, 2006). Não obstante, a partir da década de 90, o projeto neoliberal estaria se tornando hegemônico em alguns países latino-americanos, o que teria como efeito a produção de novas lógicas e orientações para a ação dos indivíduos, bem como novas concepções acerca de política (DAGNINO, 2004, 2006). Convém observar que esse deslocamento de significados tem impacto também na cultura política, uma vez que altera as orientações dos indivíduos em relação ao sistema democrático e a seu papel dentro dele:

O avanço da estratégia neoliberal determinou uma profunda inflexão na cultura política no Brasil e na América Latina. Assim, menos reconhecida e debatida do que a reestruturação do Estado e da economia que têm resultado da implementação desse projeto, há uma redefinição de significados no âmbito da cultura que integram a transformação que tem se operado nos nossos países (DAGNINO, 2004, p. 200).

caridade. No mesmo sentido, o conceito de participação também passa a ter uma perspectiva privatista e individualista, em substituição à idéia de participação social, coletiva, através da constituição de espaços públicos. E o conceito de sociedade civil se desloca de uma noção mais ampla e inclusiva de espaço para representações de interesses heterogêneos da sociedade, como por exemplo, através de movimentos sociais, para uma noção restrita e seletiva da participação de ONGs, fundações empresariais filantrópicas, e outras organizações do terceiro setor vistas como parceiras ou complementares às funções do Estado. Quanto ao significado de democracia e política pode-se dizer que no projeto neoliberal esses termos remetem a noções mais minimalistas, de representação no sistema político formal, ao passo que o projeto democrático-participativo concebe noções mais ampliadas de democracia e política, com participação social e sociabilidade.

REVISTA DEBATES, Porto Alegre, v. 2, n. 2, p. 70-102, jul.-dez. 2008. 76 


\section{Cultura, movimentos sociais e produção simbólica}

A dimensão de disputa simbólica e sua relação com a ação coletiva também é abordada por Della Porta e Diani (1999). Eles apresentam uma noção próxima à de projetos políticos para explicar a ação dos indivíduos em relação à política e sua participação em movimentos sociais ${ }^{5}$. O conceito utilizado é o de frame (traduzido como quadro ou enquadramento). Os autores definem frames como "esquemas de interpretação que permitem aos indivíduos localizar, perceber, identificar e classificar ocorrências dentro de seu espaço de vida e do mundo como um todo" (DELLA PORTA e DIANI, 1999, p. 69). São essas estruturas interpretativas que permitem aos indivíduos conceber e interpretar determinados fenômenos ou processos sócio-políticos como problemas - problemas em torno dos quais a ação coletiva poderia ser reconhecida como forma legítima e desejável de mudança. Uma vez que esses frames ou estruturas interpretativas são construídos simbolicamente - através da definição de sentidos e produção de significados para idéias e conceitos que tornam possível a apreensão e interpretação da realidade -, eles são também objetos de disputa entre vários atores com projetos e interesses distintos, sendo o vencedor aquele que sucede em ser reconhecido e legitimado para falar em nome de certos interesses e tendências (DELLA PORTA e DIANI, 1999).

Dentre esses atores em disputa pela construção simbólica de quadros interpretativos estariam os movimentos sociais - ou mais especificamente, as organizações de movimentos sociais ${ }^{6}$. Com efeito, Della Porta e Diani apontam para a utilidade da noção de frames para compreender e estudar movimentos sociais:

\footnotetext{
${ }^{5}$ Movimentos sociais são definidos por Della Porta e Diani como: "redes informais, baseadas em crenças compartilhadas e solidariedade, que se mobilizam em torno de temas conflituosos através do uso freqüente de várias formas de protesto" (1999, p. 16).

${ }^{6}$ Para os autores movimentos sociais não são organizações, são redes de interação. Contudo, eles podem incluir ou não organizações formais dependendo das circunstâncias e do momento em que eles se encontram. Portanto, uma organização formal não é um movimento social, mas pode ser parte de um. Nas fases de formação e consolidação dos movimentos um sentimento coletivo tenderia a prevalecer, mas na medida em que esse sentimento de pertencimento passa a significar pertencer exclusivamente à organização do movimento, ele tenderia a se enfraquecer enquanto tal e, no limite, desaparecer.
}

REVISTA DEBATES, Porto Alegre, v. 2, n. 2, p. 70-102, jul.-dez. 2008. 77 


\begin{abstract}
A análise de frames nos permite capturar o processo de atribuição de significados, que está por trás da explosão de qualquer conflito. De fato, a produção simbólica nos permite atribuir a eventos e comportamentos, de indivíduos ou grupos, um significado que facilita a ativação da mobilização (DELLA PORTA e DIANI, 1999, p. 69).
\end{abstract}

Nesse contexto, as práticas dos movimentos sociais seriam passíveis de serem interpretadas como "praxis cognitiva que inclui um processo incessante de produção e reprodução de códigos culturais" na medida em que, "um componente chave da atividade dos movimentos está mais ou menos diretamente relacionada com a produção simbólica" (DELLA PORTA e DIANI, 1999, p. 68-69).

A produção simbólica levada a cabo pelos movimentos sociais implica em alguns elementos e processos fundamentais para a compreensão da dinâmica dos movimentos sociais argentinos. Primeiramente, a construção social simbólica de problemas consiste, em grande medida, na identificação dos responsáveis pela situação - no caso dos movimentos argentinos, como veremos mais à frente, houve uma espécie de consenso no tocante à culpabilidade do modelo neoliberal. Em segundo lugar, a construção simbólica de uma estrutura interpretativa implica mais do que a identificação de problemas, mas também busca de soluções, discussão sobre a criação de novos padrões sociais e de novas formas de regular a relação entre grupos, e novas articulações de consenso e de exercício do poder (DELLA PORTA e DIANI, 1999) - processos que estiveram presentes nos movimentos sociais argentinos estudados. A construção simbólica por parte de um movimento envolve também a transformação da identidade dos atores, de modo que eles possam identificar a mobilização como possível, legítima e desejável; ou seja, para que eles resolvam agir coletivamente, participando de um movimento ou de um protesto, é necessário que estejam convencidos, individualmente, das 
oportunidades e da necessidade da mobilização (DELLA PORTA e DIANI, 1999).

Portanto, para que um movimento tenha sucesso em suas tentativas de mobilização, é necessário que haja um alinhamento entre (a) sua estrutura interpretativa e as mensagens e concepções transmitidas a partir dela, e (b) as orientações e componentes culturais característicos de determinada população e derivados de sua herança cultural. Mas a idéia de que tal alinhamento é possível pressupõe a existência de uma relação dinâmica entre o desenvolvimento do movimento e a herança cultural do país em que ele está. De fato, Della Porta e Diani argumentam que os movimentos emergentes extraem elementos tanto de sua herança tradicional como de percepções que se opõem a ela - apresentando-as a partir de uma nova perspectiva. Nesse sentido, a ação coletiva seria tanto uma construção ou manipulação inovadora de símbolos como também uma reafirmação da tradição, ou uma confirmação da "continuidade de valores e memórias históricas que haviam sido, nos tempos recentes, negligenciados ou esquecidos" (DELLA PORTA e DIANI, 1999, p. 76). Importa notar que essa relação dinâmica e dialética entre cultura e movimentos sociais faz lembrar bastante a relação entre cultura política e projetos políticos concebida por Dagnino (2006) - dentro desta perspectiva, podemos considerar determinados movimentos sociais como representantes ou expressões de um projeto político específico.

A relação entre tradições históricas culturais e ação social, no âmbito de uma nação, também é trabalhada por Grimson (2004) em sua análise sobre a influência de experiências históricas sedimentadas na memória coletiva dos argentinos - tais como o peronismo, o genocídio do regime militar e a hiperinflação - sobre mobilizações e protestos recentes da população. De acordo com Grimson, as experiências históricas marcantes, compartilhadas pelos argentinos ao longo do tempo, são constitutivas de modos de imaginação, cognição e ação dos atores sociais. Do argumento do 
autor é possível apreender que tais experiências históricas seriam também constitutivas da cultura política. A seguinte afirmação ilustra esse ponto:

[...] a sedimentação da experiência histórica também incide nos modos de negociação e enfrentamento com distintos graus de radicalidade, em modos de organização mais ou menos verticais ou clientelistas, em concepções acerca dos tempos e espaços do protesto (GRIMSON, 2004, p. 186).

Mas as experiências históricas sedimentadas seriam constitutivas não apenas da cultura política argentina, como também da cultura entendida em um sentido mais amplo: "[...] culturas não são essências nacionais. Tampouco são construções estratégicas. São o resultado da sedimentação e elaboração de experiência históricas" (GRIMSON, 2004, p. 190).

Em consonância com os outros autores tratados aqui, que trabalham com noções de cultura e cultura política, Grimson ressalva que não pressupõe a existência de uma cultura única e homogênea, com modos de ação, organização e sentidos de espaço e tempo uniformes. Ele pressupõe, todavia, que existem padrões culturais prevalecentes, e que esses são compreensíveis e explicáveis, em grande medida, por meio de "experiências históricas nacionais que podem se fazer presentes em momentos chave, inclusive e maneira dramática, como limites da imaginação política" (GRIMSON, 2004, p. 187).

Assim como Grimson (2004), Della Porta e Diani reconhecem que a cultura é uma importante dimensão explicativa da ação. Com efeito, é ela quem molda o repertório de "hábitos, habilidades e estilos a partir dos quais as pessoas constroem estratégias de ação. Em outras palavras, a cultura provê o aparato cognitivo que as pessoas precisam para se orientar no mundo" (DELLA PORTA e DIANI, 1999, p. 67). Tal aparato cognitivo consiste em "uma multiplicidade de elementos culturais e ideacionais que incluem crenças, cerimônias, formas artísticas e práticas informais como a linguagem, conversa, estórias, rituais diários" (SWIDLER apud DELLA 
PORTA e DIANI, 1999, p. 68). Aproximando-se de Dagnino (2006) e Avritzer (2002), Della Porta e Diani (1999) reconhecem que dentro de uma única sociedade podem existir diversos modelos culturais, e, por conseguinte, diversas estruturas interpretativas (interpretative frames). Todavia, assim como aqueles autores, estes também indicam que em certos momentos e contextos podem emergir estruturas interpretativas dominantes, às quais "elaborações especificas de várias organizações e movimentos podem ser reduzidas" (DELLA PORTA e DIANI, 1999, p. 77).

Outra importante contribuição trazida por Della Porta e Diani (1999) acerca dos determinantes externos da ação dos movimentos diz respeito ao grau de incorporação de suas reivindicações e representações no discurso e prática de atores institucionalizados. Quando as representações produzidas pelos movimentos são incorporadas rapidamente por estes atores, o espaço para continuidade do movimento tende a ser reduzido. Com efeito, no caso de alguns dos movimentos argentinos essa proposição foi verificada - em grande medida com o início do governo Kirchner.

Cumpre ressalvar que embora o marco teórico no qual este trabalho se fundamenta dê um papel destacado à dimensão simbólica dos movimentos sociais - o que se justifica na medida em que nosso propósito é analisar a relação destes movimentos com a cultura política -, não se trata de uma negligência das demandas por recursos materiais tão características da ação dos movimentos argentinos. Com efeito, assim como Della Porta e Diani argumentam, entendemos que há uma forte conexão entre a ação no nível simbólico e a ação direcionada para o controle de recursos materiais. Mesmo que os objetivos do movimento digam respeito a recursos econômicos ou aumento de poder decisório e não a mudanças no estilo de vida e nos códigos culturais, é a representação adequada da situação dos atores sociais por eles próprios, ou seja, seu auto-entendimento da situação em que se encontram, que torna possível a avaliação de quais recursos materiais eles poderiam ou desejariam dispor e quais seriam passíveis de demandar.

REVISTA DEBATES, Porto Alegre, v. 2, n. 2, p. 70-102, jul.-dez. 2008. 81 
Segue-se uma discussão sobre o que se tem entendido e produzido sobre a idéia de cultura política na América Latina, o que será contrastado com o contexto argentino - a lógica de ação e o caráter dos movimentos sociais contemporâneos neste país. Essa discussão será feita à luz dos modelos teóricos apresentados até aqui, buscando-se analisar em que medida eles contribuem para a compreensão do caso argentino.

\section{Visões de cultura política na América Latina}

Entre os diversos autores que têm pensado e escrito sobre cultura política na América Latina pode-se dizer que existem alguns pontos de convergência. Um deles é a idéia de que os países latino-americanos se caracterizam por uma cultura política híbrida, na qual convivem, ao mesmo tempo, orientações e práticas sociais autoritárias - caracterizadas por relações verticais, hierárquicas, práticas clientelistas e patrimonialistas -, ao lado de instituições políticas formalmente democráticas (BAQUERO, 1994; AVRITZER, 2002; CASTRO, 1998; DAGNINO, 2006; SANTOS, 1993).

Marcello Baquero (2001) aponta para esse descompasso entre a prática cotidiana nos países latino-americanos e os direitos definidos formalmente:

\footnotetext{
$\mathrm{Na}$ cotidianidade, os setores sociais parecem ter-se acostumado a um estado de subordinação, onde predomina a hierarquia social e a relação com o Estado continua a se dar preponderantemente em termos de clientelismo e paternalismo, e não via o cumprimento de direitos e obrigações (BAQUERO, 2001, p. 51).
}

Segundo Baquero tal assimetria estaria relacionada a uma noção débil de cidadania e à institucionalização de identidades coletivas verticais agrupadas nas categorias líder-povo, "as quais praticamente fazem parte da cultura da região" (BAQUERO, 2001, p. 53). Esses elementos seriam, portanto, constitutivos da cultura política latino-americana, a qual, na visão de Baquero, poderia ser entendida como não-democrática em vários 
sentidos. Algumas afirmações feitas pelo autor expressam essa visão, como, por exemplo, quando ele se refere a um "tipo de cultura política em que prevalecem traços políticos convencionais como clientelismo, paternalismo, patrimonialismo e personalismo" (BAQUERO, 2003); ou a uma "cultura política fragmentada, com pré-disposição ao individualismo e à pouca valorização do coletivo" (BAQUERO, 2003).

Embora ele reconheça os ganhos experimentados no contexto das transições democráticas - em matéria de re-significação de conceitos e ampliação da idéia de democracia - pode-se perceber, nos trabalhos de Baquero, uma visão menos otimista e mais estática (do que a de outros autores) acerca de cultura política latino-americana. Com efeito, ele aponta para o fato de que, "[...] a tradição autoritária, bem como a instabilidade política permanente, não têm proporcionado as bases fundamentais para a construção e a consolidação de uma cultura política ativa e fiscalizadora" (BAQUERO, 2001, p. 63). A ausência dessa dimensão ativa e fiscalizadora da cultura política é vista como um dos problemas centrais em alguns países latino-americanos e uma das indagações que Baquero propõe é: "como gerar organizações que capacitem os cidadãos como participantes mais ativos e fiscalizadores de seus representantes" (BAQUERO, 2003). Cumpre notar, contudo, que no caso da Argentina a dimensão ativa e fiscalizadora por parte da sociedade se faz mais presente do que em outros países latino-americanos. A própria crise política de 2001 pode ser compreendida no contexto de uma exacerbação dessa dimensão - que continuou caracterizando a ação dos movimentos sociais.

O caráter híbrido e dissonante da cultura política dominante na América Latina também é apontado por Avrtizer (2002) e Dagnino (2006). A última o apreende em termos da convivência entre um autoritarismo social e a forma democrática adotada nos países latino-americanos com o fim dos regimes autoritários. Dagnino entende autoritarismo social como "uma cultura que legitima as diferenças sociais, que internaliza os códigos que hierarquizam as classes e os grupos sociais e os organizam em 
categorias com base no seu pertencimento de classe, raça, gênero" (DAGNINO, 2006, p. 45). Esse autoritarismo social seria, na concepção da autora, um elemento de longa presença histórica na cultura latinoamericana, não tendo mudado substancialmente, mesmo com as redemocratizações.

Avritzer (2002) concebe a cultura política nos países da América Latina como marcada por um hibridismo tanto na esfera do sistema político como na esfera pública; o que teria conseqüências fortemente antidemocráticas. Ele traça as origens desse hibridismo remetendo a três processos históricos: a) ambigüidade relacionada à forma de democracia adotada nos países latino-americanos, que ao mesmo tempo em que tomaram a tradição liberal como referência constitutiva sofreram a influência da tradição ibérica, cujo elemento central seria "a aceitação de uma ordem social hierárquica, diversificada e compartimentada funcionalmente" (MORSE apud AVRITZER, 2002, p. 70); b) transferência de instituições de democracias liberais de forma não crítica e sem considerar o contexto cultural de cada país; c) assimilação da cultura popular juntamente com elementos modernos europeus na identidade nacional. $O$ hibridismo teria resultado na dificuldade para implementação da democracia e para a construção de um espaço público igualitário na América Latina, gerando efeitos negativos na organização e funcionamento de três instituições próprias da democracia: relações entre público e privado, formas públicas de associação e natureza da mobilização popular.

Embora considere o hibridismo político como a "cultura política hegemônica formada na América Latina" (AVRITZER, 2002, p. 75) ${ }^{7}$, Avritzer atenta para a necessidade de diferenciar os casos nos quais a hibridização impede a existência de igualdade deliberativa dos casos onde novas práticas emergem no nível público. Essa diferenciação é fundamental para o desenvolvimento de seu argumento (2002), cuja hipótese central é a de

7 As duas tendências principais características dessa cultura política híbrida seriam: instrumentalidade em relação a instituições políticas e desigualdade deliberativa no nível público.

REVISTA DEBATES, Porto Alegre, v. 2, n. 2, p. 70-102, jul.-dez. 2008. 84 
que novas formas de interpretação e avaliação de algumas instituições políticas e re-significações do conceito de democracia - expressos em práticas e experiências recentes de formação de públicos participativos representariam uma ruptura com tradições políticas tradicionais da cultura política latino-americana. Com efeito, Avritzer considera que essas novas formas de conceber e interpretar elementos da tradição democrática ganharam espaço durante o processo de transições democráticas na América Latina. Nesse contexto, e devido em grande medida à ação dos movimentos sociais surgidos na época (tal como os de direitos humanos na Argentina), teriam emergido novas tradições políticas na América Latina, quais sejam: ocupação da esfera pública para dar voz a demandas políticas, mobilizações coletivas em torno de demandas e identidades plurais e formação de associações voluntárias organizadas de forma autônoma em relação ao Estado.

Mudanças ocorridas nas formas de expressão (que tiveram como efeito a formação de novos entendimentos acerca dos objetivos e do caráter da ação política); nas identidades dos atores sociais, que passaram a ter um caráter mais plural e democrático; e nas formas de associação, que passam a questionar o papel dos mediadores políticos e da determinação de políticas pelo Estado, representam, para Avritzer, um esforço significativo no sentido de mudar os padrões heterônomos de associação e representação na América Latina.

Assim como Dagnino (2004, 2006), Avritzer entende as mudanças de significado, concepções e visões acerca da ação política, ocorridas no período de transição democrática, como ganhos significativos para um projeto de democracia mais participativo e amplo, não limitado a uma visão minimalista de democracia liberal. Mas, além disso, ele vê nessas mudanças um potencial transformador das práticas políticas tradicionais dominantes na América Latina, ou seja, uma possibilidade de ruptura com aquilo que ele entende como cultura política hegemônica local:

REVISTA DEBATES, Porto Alegre, v. 2, n. 2, p. 70-102, jul.-dez. 2008. 85 
As transformações também implicaram em uma mudança na relação entre público e privado. A cultura do favor e as intermediações política clientelistas começaram a dar lugar a formas mais autônomas de organização social (AVRITZER, 2002, p. 86).

Embora compartilhe importantes pressupostos com Dagnino, Avritzer não dá tanta ênfase ao projeto neoliberal como ameaça a essa concepção de democracia participativa e deliberativa. Nesse sentido, o trabalho de Dagnino fornece diferentes e importantes instrumentos analíticos para a análise dos movimentos sociais argentinos. Contudo, a visão de Avritzer de que novas práticas políticas e re-significações de conceitos como participação, ação política, associação e democracia, representariam uma mudança de cultura política ou o surgimento de uma nova cultura política popular, diferente da tradicional, converge com o que argumentamos neste trabalho: que a produção simbólica, as práticas e formas de ação coletiva levadas a cabo pelos movimentos sociais argentinos estudados representam certo grau de ruptura em relação ao que a literatura específica entende por cultura política tradicional latinoamericana.

Passemos então à discussão dessa hipótese a partir da apresentação e discussão dos três movimentos sociais referidos ${ }^{8}$. Eles serão analisados à luz, principalmente, das abordagens teóricas propostas por Dagnino (2006), Avritzer (2002) e Della Porta e Diani (1999).

\section{Movimentos sociais argentinos e re-significação da cultura política}

Os movimentos sociais surgidos na Argentina ao longo da década de 90 - constituídos por organizações de desempregados, trabalhadores de empresas recuperadas e assembléias de bairro - devem ser apreendidos em um contexto de desgaste do modelo neoliberal e conseqüente crise, tanto econômica como sócio-política. A crise política de 2001, que culminou

\footnotetext{
${ }^{8}$ A escolha dos movimentos a serem analisados se deve, em grande medida, à contribuição dos trabalhos de Palomino, Lascano, Pogliaghi e Rajher (2006), Briones, Fava e Rosan (2004) e Catela (2004).
}

REVISTA DEBATES, Porto Alegre, v. 2, n. 2, p. 70-102, jul.-dez. 2008. 86 
na queda do presidente De la Rúa, foi o desfecho de uma crise econômica que tinha, em sua origem, o desgaste do projeto neoliberal (PALOMINO et al, 2006; BRIONES, FAVA e ROSAN, 2004) e do modelo de paridade fixa do cambio. Políticas neoliberais vinham sendo implementadas no país desde o final da década de 70, ainda durante o regime autoritário. Contudo, um programa neoliberal só foi aplicado no país de forma sistemática a partir da década de 90, durante o governo Menem. Com efeito, nessa época o governo promoveu uma abertura unilateral da economia (notadamente para o comércio com os Estados Unidos); atrelou o valor da moeda nacional ao dólar (o que levaria a um aumento da dívida externa), realizou privatizações de empresas do setor público, de forma muito mais indiscriminada do que no Brasil, reformas no sistema previdenciário e descentralização do sistema de saúde e educacional.

As privatizações iniciadas ainda na primeira metade da década de 90 levaram a um aumento significativo no número de desempregados (e como veremos, foi nessa época que começaram a se articular as primeiras organizações de desempregados). Mais tarde, dada sua insustentabilidade diante da dívida externa, o sistema de paridade fixa foi abandonado, dando início a um significativo processo inflacionário. A crise econômica levou não só a uma insatisfação generalizada em relação ao modelo neoliberal, como também a uma reprovação e intolerância por parte de setores amplos da sociedade em relação à classe política - e em alguns casos em relação ao sistema político de modo geral - que culminaram em um agravamento da crise política e renúncia do presidente.

É nesse contexto de crise e de questionamento do projeto político neoliberal que surgem os movimentos sociais argentinos contemporâneos ${ }^{9}$.

\footnotetext{
${ }^{9}$ Optamos por não utilizar a expressão novos movimentos sociais que, de acordo com Melucci teria sido formulada em um contexto no qual a pesquisa sobre movimentos tinha a função temporária de "indicar um número de diferenças comparativas entre as formas históricas de conflitos de classe e as formas emergentes de ação coletiva" (MELUCCI, 1996, p. 5), caracterizadas por demandas mais abrangentes relacionadas a questões de identidade, gênero, etc. Em contrapartida, o autor aponta que há, na literatura corrente, uma apropriação inadequada da expressão novos movimentos sociais na medida em que ao utilizá-la não se especifica as características distintivas que dão aos movimentos o caráter de novidade.
}

REVISTA DEBATES, Porto Alegre, v. 2, n. 2, p. 70-102, jul.-dez. 2008. 87 
As articulações e organizações de trabalhadores desempregados - que mais

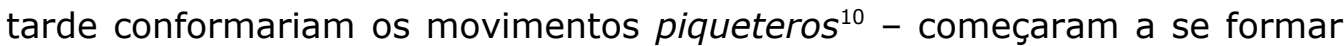
no contexto das privatizações de grandes empresas nacionais, ainda no início da década de 90. Com efeito, face ao índice crescente de desemprego, parte do setor de desempregados começou a se organizar coletivamente para demandar emprego, subsídios, e bolsas de alimentos (PALOMINO et al, 2006). As formas de mobilização coletiva e protesto levados a cabo por essas organizações de desempregados foram, essencialmente, os piquetes - bloqueios de estradas com pedras, galhos de árvores e queima de pneus (CATELA, 2004) -, daí a denominação piqueteros.

Javier Auyero (2002) oferece importante contribuição para a análise dessas formas de protesto. Ele argumenta que a beligerância social verificada na Argentina a partir da década de 90 não deve ser entendida como uma resposta mecânica à falta de emprego e à pobreza geradas pelas reformas neoliberais. Embora o contexto social externo constitua a base sob a qual as mobilizações e protestos se erigem, "as maneiras pelas quais as pessoas formulam suas reclamações têm a ver com a política e com a cultura da ação coletiva" (AUYERO, 2002, p. 3). Ou seja, as formas de protesto e o caráter da beligerância social emergem a partir de estruturas interpretativas específicas e formas de auto-representação dos protagonistas do protesto, constituídas a partir do aprendizado com experiências passadas e interação com o Estado. Nesse sentido Auyero assinala que a ação coletiva dos protagonistas da recente beligerância social é orientada por uma identidade coletiva que foi se formando no início

10 Às várias organizações de desocupados conformadas no final da década de 90 se atribuiu o nome de movimentos piqueteiros devido à forma de protesto utilizada por esses grupos: piquetes com os quais cortavam rotas. Dentre os movimentos piqueteros mais importantes no contexto do final da década de 90 e início do século XXI estão o Movimiento Teresa Rodríguez (MTR), o Polo Obrero (ligado ao Partido Obrero), o Movimiento Independiente de Jubilados y Desocupados (MIJD), Movimiento de Trabajadores Desocupados Aníbal Verón (MTD Aníbal Verón), Federación de Tierra y Vivienda (FTV) e Barrios de Pie. Cumpre ressalvar que com o início do Governo Kirchner observou-se uma desmobilização dos dois últimos movimentos que tinham tido sido importantes protagonistas nos protestos até 2003 - consoante a uma incorporação e alinhamento destes ao novo governo.

REVISTA DEBATES, Porto Alegre, v. 2, n. 2, p. 70-102, jul.-dez. 2008.88 
da década de 90 e que tomou a forma de uma identificação comum como povo em oposição à figura dos políticos e funcionários associados com a corrupção. O sentimento de insatisfação e intolerância em relação a todos os políticos, somado ao desemprego e às privações materiais - que passa a definir a nova identidade dos atores sociais - seria expresso mais tarde na simbologia do "que se vayan todos, que no quede ni uno solo" (BRIONES, FAVA e ROSAN, 2004).

Partindo de mobilizações - em cidades das regiões mais atingidas pelo desemprego (Salta e Neuquén) no início da década de 90 - que agregavam desempregados, trabalhadores da área de educação e saúde e grande parte da população insatisfeita com os resultados das reformas neoliberais e com os escândalos de corrupção (AUYERO, 2002), o movimento piqueteiro foi ganhando maior amplitude e visibilidade no país ao longo da década de 90 . E culminou, em 2001, juntamente com outros setores sociais organizados, na explosão de beligerância social onde os protagonistas não mais se identificavam como membros de determinada classe ou sindicato, mas sim como "todo el pueblo" (AUYERO, 2002).

As principais reivindicações do movimento piqueteiro estiveram direcionadas à obtenção de recursos materiais tangíveis, e nesse sentido, mais além da ação coletiva de protesto, existe outra face desse movimento, que denota uma construção social bem mais ampla. Com efeito - em que pese sua heterogeneidade e diferenças em relação a orientações políticas e espectros ideológicos - todas as organizações de desempregados têm em comum o trabalho no âmbito territorial dos bairros, que conformam suas bases. Nesse sentido Svampa (2008) aponta que na crescente perda do universo trabalhista como fonte de identificação, haja vista o crescente desemprego, os bairros passam a ocupar esse espaço de referência social, aparecendo como o lugar privilegiado para a "re-significação e emergência da ação coletiva" (SVAMPA, 2008, p. 172). Os movimentos de trabalhadores desempregados têm, portanto, importante matriz territorial, e que está intimamente ligada à ajuda social, uma vez que as principais 
atividades desenvolvidas nos bairros são o manejo de comedores e merendas, a realização de atividades produtivas coletivas, dentre outras iniciativas comunitárias. Contudo, como aponta Svampa (2008), à diferença das redes clientelistas de ajuda social mútua feita através de mediadores ligados ao Partido Justicialista $(\mathrm{PJ})^{11}$, e que realizavam atividades sociais supostamente apolíticas, os mediadores locais que surgem nas bases dos movimentos de trabalhadores desempregados são, no mais das vezes, militantes de esquerda não ligados ao PJ e alguns não ligados diretamente a nenhum partido de esquerda. Observe-se que esta nova forma de militância surge em oposição à anterior, dominada pelo aparato do PJ, e busca superar suas formas clientelistas de relação política. Contudo cumpre observar que, em que pese o crescimento e o aumento do número de membros das organizações piqueteiras até 2002, a forma peronista/justicialista de militância social no nível dos bairros seguiu sendo hegemônica (SVAMPA, 2008, p. 178).

No tocante às formas de ação política os movimentos piqueteiros, como apontamos anteriormente, se caracterizam pelas ações coletivas diretas, com destaque para o corte de estradas - com matizes mais ou menos radicais, como aponta Vitullo (2005) - mas também pela dinâmica de assembléias para a tomada de decisão e pelos trabalhos de base mencionados acima.

Cumpre notar que há diferentes atribuições de significado à idéia de ação política - de acordo com a orientação de cada organização. Ao passo que algumas dessas organizações de desempregados interpretam o significado de ação política como direcionada para a esfera institucional - o que orienta sua ação no sentido de tentar influenciar e produzir impacto

11 No tocante a este tema cabe referenciar o trabalho de Auyero (2000) sobre redes de sobrevivência e ajuda mútua em comunidades pobres no Conurbano Bonaerense. O autor demonstra como o PJ se utiliza da situação de extrema pobreza e privação material da população de determinadas regiões para a manutenção de suas bases de sustentação local. A partir de pesquisa etnográfica Auyero investiga profundamente as relações de clientelismo com o propósito de entender qual o significado de tais relações para os agentes políticos do partido peronista - que buscam formas de legitimá-las e garantir sua continuidade através da mobilização de elementos da simbologia do peronismo - e para a população pobre que recebe o auxílio.

REVISTA DEBATES, Porto Alegre, v. 2, n. 2, p. 70-102, jul.-dez. 2008. 90 
sobre o sistema político formal -, outras organizações interpretam a ação política como voltada para a dimensão de mudança social a nível local, como por exemplo, o MTD Aníbal Verón destacado por Vitullo (2005).

Uma discussão sobre a heterogeneidade do vasto campo piqueteiro e do processo de fragmentação que o caracterizou está presente em Vitullo (2005). O autor faz uma distinção entre os piqueteiros duros e os mais brandos, recebendo os últimos esta denominação por serem mais abertos à negociação com o Estado. Svampa (2008) também aponta para três tendências principais dentro do movimento piqueteiro: os grupos dependentes de partidos políticos (com destaque para o $\mathrm{PO}^{12}$, MST TV ${ }^{13}$ e $\mathrm{MTL}^{14}$ ); os grupos independentes, que seriam o que Vitullo chama de autonomistas, com destaque para o MTD Aníbal Verón; e os grupos de matriz nacional-populista, caracterizados pela consolidação de um líder personalista, com destaque para a FTV de Luis D'Elia.

Em que pesem as distintas orientações e devido em grande parte à sua dinâmica de assembléias, trabalho a nível local e formas de ação coletiva que contribuíram para a construção de solidariedade e de identidades coletivas distintas, os movimentos piqueteiros levaram, naquele contexto, à constituição e sedimentação de novas práticas sociais, contribuíram para a ampliação do significado de ação política e para a resignificação da idéia de cidadania, que passa a adquirir um caráter mais coletivista e comunitário e menos individualista, no marco de um processo de mudança de referenciais e de novas formas de identificação coletiva. Dessa forma, pode-se sugerir que o movimento piqueteiro, considerando-se as diferenças entre seus distintos matizes, estaria inserido dentro de um projeto político mais amplo (entendido nos termos propostos por Dagnino), e teria resultado em uma mudança cultural nos padrões de organização e regulação das relações sociais de pelo menos uma parcela da sociedade.

\footnotetext{
12 Polo Obrero, ligado ao Partido Obrero.

13 Movimiento sin Trabajo Teresa Vive, vinculado ao partido Movimento Socialista dos Trabalhadores (MST).

${ }^{14}$ Movimento Territorial de Liberación, ligado ao Partido Comunista.
} 
Nesse mesmo sentido, referindo-se aos movimentos piqueteiros, Palomino et al assinalam que "as práticas democratizantes, a tomada de decisão aberta, consensual, coletiva, e igualitária, o debate em torno das formas de produzir e o destino do excedente são temas que estão presentes em todas as experiências de raiz mais social" (PALOMINO et al, 2006, p. 318). Cabe observar que os movimentos piqueteros tiveram seu auge no contexto da crise de 2001. Nesse contexto, e ao longo do ano 2002, suas demandas obtiveram resultados significativos, com a ampliação de planos sociais de emergência e outros subsídios. Contudo, depois de 2003 com a entrada de Kirchner e a redução dos níveis de desemprego esses movimentos perderam em termos de magnitude e de centralidade na cena política argentina. Isso se deveu a várias razões, dentre elas o desgaste das formas de protesto (notadamente corte de estradas, ruas e pontes) re-afirmado e reforçado por uma campanha anti-piqueteira por parte do governo e da grande mídia (SVAMPA, 2008), estratégia Kirchner de cooptação de alguns setores e redução do desemprego, que foi de cerca de 3 milhões de desempregados em 2002 e 2003 a 1,5 milhões no primeiro semestre de 2007 (Subsecretaría de Programación Técnica y Estudios Laborales- MTESS apud PALOMINO, 2008).

Cabem, contudo, algumas ressalvas quando falamos em novos padrões de organização e regulação das relações sociais e políticas. Alguns dos movimentos piqueteiros estão diretamente vinculados com partidos políticos, incluso com o próprio partido de Kirchner, Frente para la Victoria, dissidência do justicialismo de Duhalde. Os movimentos que se sujeitam a uma organização partidária se relacionam de distintas maneiras com os partidos, uns optando por intervir de maneira direta no sistema político, através da eleição de representantes, outros preferindo participar indiretamente, por meio de representantes a quem se vinculam. As relações entre movimentos e partidos incluem, em determinados casos, práticas de clientelismo (PALOMINO et al, 2006). E nesse sentido cabe observar a influência que a distribuição de planos sociais pelo governo tem 
na reprodução de tais práticas. Feitas essas observações, voltemos ao estudo dos casos passando à análise do movimento de trabalhadores de empresas recuperadas.

As origens do movimento dos trabalhadores de empresas recuperadas remetem à segunda metade da década de 90, quando se deram as primeiras experiências de recuperação de empresas. A recuperação de empresas é um termo que se refere, originalmente, ao processo pelo qual trabalhadores de determinada fábrica ou empresa falida e abandonada pelos proprietários assumem a gestão da empresa com o propósito de recuperar os postos de trabalho que haviam perdido. Eles o fazem por meio do estabelecimento de um novo regime jurídico e adotando, na maioria das vezes, o sistema de cooperativas para a administração da empresa ${ }^{15}$. A partir dessas experiências, que se multiplicaram após a crise de 2001, e cujo objetivo principal seria o de recuperar e sustentar a fonte de trabalho (PALOMINO et al, 2006), se configurou o Movimento Nacional de Empresas Recuperadas. Assim como no caso dos movimentos piqueteiros, este movimento não é unificado. Há, ao contrário, uma competição entre as diversas correntes, principalmente no que diz respeito a quais deveriam ser as orientações políticas, objetivos e métodos de luta, do movimento.

As orientações dentro do movimento vão desde aquelas que reivindicam apenas a recuperação dos postos de trabalho, passando pelas que demandam a desapropriação e auto-gestão, até aquelas cujo objetivo é não permitir mais a destruição de postos de trabalho - o que seria possível através da estatização de todas as empresas e sua gestão pelos trabalhadores. Em que pese o maior ou menor radicalismo de suas diversas correntes, a lógica de ação e a própria estrutura interpretativa-cognitiva do movimento pressupõe uma ruptura com preceitos básicos do projeto

15 Existem atualmente no país um pouco mais de 200 empresas recuperadas, todas de pequeno e médio porte (PALOMINO et al, 2006). As primeiras experiências de recuperação foram levadas a cabo pelos trabalhadores da fábrica têxtil Brukman, de Buenos Aires, e pelos trabalhadores da fábrica ceramista Zanón, de Neuquén.

REVISTA DEBATES, Porto Alegre, v. 2, n. 2, p. 70-102, jul.-dez. 2008. 93 
neoliberal e do sistema capitalista. Com efeito, a idéia de que trabalhadores possam assumir a gestão e a administração jurídica de uma empresa - que, portanto não mais seria propriedade privada - põe em xeque um dos princípios básicos do capitalismo, o direito à propriedade privada.

Nesse sentido, assim como apontam Palomino et al (2006), o impacto deste movimento não estaria tanto em sua magnitude ou visibilidade, mas sim em sua dimensão simbólica, referente à reformulação de quadros cognitivos dominantes na sociedade argentina - ainda que em escala limitada. O movimento de trabalhadores de empresas recuperadas não tem uma forma de protesto específica, tampouco capacidade de mobilização tal como tiveram os movimentos piqueteiros, contudo, membros daquele movimento muitas vezes se articularam com estes, o que conferiu ao primeiro maior capacidade de ação e visibilidade.

Ainda que com resultados díspares - como, por exemplo, empresas que conseguiram a desapropriação e puderam manter a produção e sustentar os postos de trabalho, como a ceramista Zanón; empresas que ainda não conseguiram a desapropriação, mas conseguiram se manter funcionando, como é o caso do Hotel Bauen; e empresas que já estão em processo de desapropriação, mas sofreram uma queda no número de postos de trabalho e na capacidade produtiva, como a têxtil Brukman - o movimento de empresas recuperadas apresenta uma novidade em termos do significado da ação política na medida em que busca legitimidade, algumas vezes com êxito, para uma prática de auto-gestão que representa, ao mesmo tempo uma alternativa ao processo de desagregação neoliberal e um questionamento das relações de trabalho inerentes ao próprio sistema capitalista.

Diferentemente dos outros dois movimentos, as assembléias de bairro $^{16}$ não têm sua ação circunscrita a temáticas específicas, elas se

\footnotetext{
${ }^{16}$ Assembléia de bairro são: "núcleos organizados espontaneamente pelos vizinhos da cidade de Buenos Aires e de outras grandes cidades do país, para reclamar e exigir a mudança do sistema político" (PALOMINO et al, 2006, p. 313). Estiveram muito presentes entre 2001 e 2002, agregando uma quantidade massiva de vizinhos. Contudo, a partir de 2003 o número de pessoas que compareciam às reuniões das assembléias reduziu-se significativamente.
}

REVISTA DEBATES, Porto Alegre, v. 2, n. 2, p. 70-102, jul.-dez. 2008. 94 
orientam por fins mais amplos e objetivos difusos - tais como mudanças nas formas de vida e no caráter das relações econômicas e sociais. Um dos eixos centrais que orientou a ação das assembléias foi a crítica ao sistema político e elaboração de propostas alternativas para o aprofundamento da democracia (PALOMINO et al, 2006). Nesse sentido, no contexto dos novos movimentos sociais argentinos talvez as assembléias de bairro sejam as que mais se aproximam da noção de projeto político de Dagnino. Ademais, no tocante a sua lógica de ação interna e ao seu potencial de influenciar o sistema político - como veremos mais à frente -, as assembléias de bairro também se aproximam do que Avritzer chama de públicos participativos.

O contexto de ressurgimento e intensificação das atividades das assembléias de bairro foi o do auge da crise política e econômica, no final de 2001, quando das mobilizações de larga escala que questionavam a legitimidade política dos governantes e do sistema político de modo geral o que se ilustra na expressão que se vayan todos que no se quede ni uno solo, consigna presente nas manifestações. Inicialmente o movimento era caracterizado por uma participação massiva (algumas assembléias chegaram a agregar centenas de pessoas) e pela reunião em espaços públicos urbanos, tais como praças e esquinas. Dessa forma, configurou-se, assim como apontam Palomino et al, uma apropriação literal do espaço público como foro de "debates, discussões, reclamações e propostas, que contrasta com as tendências prevalecentes durante uma década de privatização dos espaços públicos, de individualismo e consumismo" (PALOMINO et al, 2006, p. 324). Posteriormente as reuniões passaram a ser realizadas em locais fechados e o número de participantes reduziu-se significativamente, chegando a uma média de vinte a quarenta pessoas por assembléia - o que contribuiu para a diminuição da visibilidade do movimento. Tal redução se deve, dentre outros fatores, a conflitos entre militantes de grupos políticos e vizinhos sem filiação e militância política, o que resultou na deserção de ambos os lados. Importa observar que as assembléias buscavam defender sua autonomia - recusando o controle e 
pressão exercidos por agrupamentos políticos externos ao movimento -, e defendiam uma democracia participativa e direta, questionando formas delegatórias de representação (os representantes tinham mandatos revogáveis e deveriam ser mais porta-vozes do que propriamente delegados).

As interações no interior das assembléias se dão de forma direta, não hierarquizada, e se busca, ao final do debate de cada tema da agenda, um consenso. As agendas de debate das assembléias são extensas e incluem diversos temas, tais como debates ideológicos gerais e temas mais específicos como meio-ambiente, desempregados, orçamento-participativo, entre outros (PALOMINO et al, 2006). Além de espaço para discussão, aprendizado e construção simbólica, as assembléias desenvolvem uma vasta gama de atividades:

\begin{abstract}
Além da participação em marchas, mobilizações, escrachos, etc., a atividade cotidiana das assembléias se desenvolve em reuniões semanais periódicas [...]. Muitas assembléias instalaram comedores e centros de ajuda escolar, promovem atividades culturais diversas, elaboram projetos e sustentam empreendimentos para gerar alternativas de emprego para desempregados e pessoas de baixa renda, etc. (PALOMINO et al, 2006, p. 326).
\end{abstract}

O contexto de (re)surgimento das assembléias, de crise, saturação e desagregação de padrões políticos e econômicos vigentes até então na Argentina, foi determinante das estruturas interpretativas que elas constituíram acerca do mundo e de si próprias. Com efeito, elas expressavam visões extremamente críticas acerca do projeto neoliberal e acerca do sistema democrático representativo e da concepção de democracia hegemônica na Argentina - que levou as assembléias a rejeitarem qualquer relação com o sistema político, incluso apoiando uma abstenção nas eleições.

Nesse sentido é lícito inferir que uma das dimensões centrais das assembléias de bairro seria sua capacidade de produzir simbolicamente 
visões de mundo, conceitos e interpretações inovadoras que podem ter impacto no sistema político, na medida em que esses conceitos, interpretações e visões de mundo são internalizados por atores institucionais. Nesse sentido Palomino et al assinalam que "o impacto político das assembléias transcende consideravelmente sua pouca presença pública atual, sobretudo porque conseguiram colocar valores renovados no espaço público" (PALOMINO et al, 2006, p. 324).

Todavia, como aponta Rossi (2005), as assembléias de bairro começam a perder a importância massiva e a centralidade que tinham adquirido no contexto sócio-político argentino a partir de abril de 2002. Isso se deveria a uma percepção de que o contexto e as oportunidades já não eram mais permissivos. Contudo, o autor aponta que o fato de terem sido episódicas não nos permite pressupor que tenham sido irrelevantes. Com efeito, argumentamos que elas representaram a construção de um conhecimento decorrente do processo de re-significação e re-interpretação da noção de democracia e política. Conhecimento este que se manteve como elemento presente nos quadros interpretativos que ainda orientam a ação de seus membros. No mesmo sentido Rossi (2005) aponta que as assembléias "percebem que já não são mais soberanas como antes eram $[\ldots]$, mas interpretam que segue sendo imprescindível deixar de delegar aos representantes as decisões se o que se quer é evitar que volte a haver abusos no poder" (ROSSI, 2005, p. 83).

No tocante aos efeitos tanto do movimento piqueteiro, como das empresas recuperados e das assembléias de bairro para o contexto sóciopolítico argentino, Palomino et al fazem, em consonância com o argumento deste trabalho, a seguinte análise:

A crise de dezembro de 2001 na Argentina recolocou a questão dos limites do espaço institucionalizado da política, abrindo lugar ao político instituidor e a uma redefinição da política [...]. É aqui que incorporamos os novos movimentos sociais, como um dos atores que desafia o instituído (PALOMINO et al, 2006, p. 332). 
E ainda:

\begin{abstract}
A politização supõe um sujeito ativo e responsável da redefinição de seu lugar na sociedade e de seu próprio devir, que pugna por ampliar o âmbito político institucionalizado questionando as fronteiras instituídas da política, do social, do econômico (PALOMINO et al, 2006, p. 333).
\end{abstract}

\title{
Conclusão
}

Considerando-se os objetivos propostos para este artigo - promover um diálogo entre os vários conceitos e categorias presentes no campo da literatura sobre movimentos sociais, democracia participativa e cultura política e discuti-los a partir da análise das práticas e características de três movimentos sociais argentinos - podemos concluí-lo em duas direções.

Em um primeiro lugar se levamos em consideração a literatura de cultura política e seus conceitos de cultura política tradicional, cultura política latino-americana, podemos concluir que a análise dos movimentos sociais argentinos contemporâneos apontaria para um processo de ruptura com as orientações predominantes acerca da idéia de política e democracia subjacentes àqueles conceitos. Em outras palavras: na medida em que a ação desses movimentos, tanto na dimensão prática como na dimensão simbólica, estaria implicando em uma re-interpretação e re-significação de vários elementos característicos daquilo que seria a cultura política latinoamericana tradicional, podemos dizer que há certo grau de ruptura no escopo desses conceitos.

Em contrapartida - e essa seria a segunda direção de nossa conclusão - categorias como cultura, quadros interpretativos (frames), projetos políticos e públicos participativos nos fornecem ferramentas teóricas e conceituais mais adequadas para a análise dos processos relativos à ação e à forma dos movimentos sociais surgidos recentemente na Argentina e nos permite analisar com mais propriedade a dinâmica da 
ruptura referida acima. Com efeito, a partir de conceitos como quadros interpretativos e projetos políticos podemos apreender as práticas e a dotação de sentido de tais práticas levadas a cabo pelo movimento piqueteiro. As mesmas noções nos permitem também entender os efeitos das ações práticas e das construções simbólicas de tal movimento para a noção de política, democracia e cidadania contexto político argentino mais amplo.

No mesmo sentido a noção de públicos participativos de Avritzer (2002) nos oferece elementos importantes para pensarmos a ação das assembléias e seu grau de (des)vinculação a decisões políticas institucionais. No tocante às empresas recuperadas cabe apontar a relevância do conceito de Dagnino de projeto político democrático como orientação para ações que se contrapõem e visam superar o projeto político neoliberal hegemônico.

Também a idéia de disputa entre projetos políticos apresentada por Dagnino é chave para a compreensão da ação dos movimentos sociais argentinos em um contexto de perda de legitimidade e de questionamento do modelo neoliberal. Nesse sentido, essa dimensão de disputa apontada por Dagnino se torna perceptível no contexto argentino. Uma disputa entre formas tradicionais de agir politicamente e de conceber a política e novas interpretações e orientações acerca da própria idéia de política.

Apontamos, por fim, que a leitura que tais conceitos e categorias nos permite fazer do significado dos movimentos sociais argentinos possibilita a apreensão do processo por meio do qual estão sendo construídos - devido em grande medida à ação dos movimentos sociais recentes - novos conceitos e novas interpretações acerca do papel do indivíduo na política e acerca do que pode ser entendido como política e como democracia.

Camila Penna é bacharel em Relações Internacionais e mestranda em Ciência Política pela Universidade de Brasília (UnB). Bolsista da CAPES/MEC. E-mail: camilapenna2003@yahoo.com.br 


\section{Referências:}

ALMOND, Gabriel; VERBA, Sidney. The Civic Culture. Boston: Little, Brown and Co., 1963.

AUYERO, Javier. Poor People's Politics: peronist networks and the legacy of Evita. Durham: Duke University Press, 2000.

. La Protesta: retratos de la beligerância popular en la Argentina democrática. Centro Cultural Rojas-UBA. Buenos Aires, 2002. Disponível em: <http://www.sunysb.edu/sociology/?faculty/Auyero/auyero> Acesso em: 02 jun. 2007.

AVRITZER, Leonardo. Democracy and the Public Space in Latin America. Princeton: Princeton University Press, 2002.

BAQUERO, Marcello. Os Desafios na Construção de uma Cultura Política Democrática na América Latina: Estado e Partidos Políticos. In:

(Org.). Cultura Política e Democracia: os desafios das sociedades contemporâneas. Porto Alegre: Editora da Universidade, 1994. p. 26-41.

. Capital Social na América Latina. In: (Org.). Reinventando a sociedade na América Latina: cultura política, gênero, exclusão e capital social. Porto Alegre/Brasília: UFRGS/CNDM, 2001. p. 50-70.

Construindo uma outra sociedade: o capital social na estruturação de uma cultura política participativa no Brasil. Revista de Sociologia e Política, Curitiba, n. 21, p. 83-108, nov. 2003. Disponível em: <http://www.scielo.br >. Acesso em: 13 out. 2006.

BRIONES, Cláudia.; FAVA, Ricardo; ROSAN, Ana. Ni todos, ni alguien, ni uno. In: GRIMSON, Alejandro (Org.). La cultura en las crisis latinoamericanas. Buenos Aires: Clacso, 2004. p. 81-106.

CASTRO, Henrique Carlos Oliveira de. Cultura Política, Democracia e Hegemonia: uma tentativa de explicação do comportamento político nãodemocrático. In: BAQUERO, Marcello; CASTRO, Henrique C. O. de; GONZÁLEZ, Rodrigo Stumpt (Orgs.). A Construção da Democracia na América Latina: Estabilidade Democrática, Processos Eleitorais, Cidadania e Cultura Política. Porto Alegre: Editora da Universidade/UFRGS, 1998. p. 3049.

REVISTA DEBATES, Porto Alegre, v. 2, n. 2, p. 70-102, jul.-dez. 2008. 100 
CATELA, Ludmila. Nos vemos en el piquete. In: GRIMSON, Alejandro (Org.). La cultura en las crisis latinoamericanas. Buenos Aires: Clacso, 2004. p. 123-144.

DAGNINO, Evelina. Confluência Perversa, Deslocamento de Sentido, Crise Discursiva. In: GRIMSON, Alejandro (Org.). La cultura en las crisis latinoamericanas. Buenos Aires: Clacso, 2004. p. 195-216.

DAGNINO, Evelina (Org.). A disputa pela construção democrática na América Latina. São Paulo: Paz e Terra, 2006.

DELLA PORTA, Donatella; DIANI, Mário. Social Movements: an introduction. Malden: Blackwell, 1999.

GONZÁLEZ, Ricardo; GUTIÉRREZ, Leandro; KOROL, Juan; ROMERO, Luis; SABATO, Hilda. Argentina: a participação popular e seus avatares (18801943). In: LAMOUNIER, Bolívar; ROUQUIĖ, Alan; SCHVARZER, Jorge (Org.). Como Renascem as Democracias. São Paulo: Brasiliense, 1985. p. 141-154.

GRIMSON, Alejandro. La experiencia argentina y sus fantasmas. In: (Org.). La cultura en las crisis latinoamericanas. Buenos Aires: Clacso, 2004. p. 177-193.

MELUCCI, Alberto. Challenging Codes: collective action in the information age. Cambridge: Cambridge University Press, 1996.

PALOMINO, Héctor. Trabajo y estado social frente a los cambios de la economía, el empleo y las relaciones laborales. Buenos Aires: UNSAM, 2008. 10 slides: color.

PALOMINO, Héctor; LASCANO, Inês; POGLIAGHI, Letícia; RAJHER, Gustavo. A Política e o Político nos Movimentos Sociais Argentinos. In: DAGNINO, Evelina (Org.). A disputa pela construção democrática na América Latina. São Paulo: Paz e Terra, 2006. p. 309-452.

ROSSI, Federico. Aparición, auge y declinación de un movimiento social: las asambleas vecinales y populares de Buenos Aires, 2001-2003. Revista Europea de Esudios Latinoamericanos y del Caribe, Madri, n. 78, p. 67-88, abr. 2005.

SANTOS, Wanderley Guilherme dos. Razoes da desordem. 2. ed. Rio de Janeiro: Rocco, 1993.

SVAMPA, Maristela. Cambio de época: movimientos sociales y poder político. Buenos Aires: Siglo Veintiuno, 2008. 
DOSSIÊ CULTURA POLÍTICA E DEMOCRACIA

VITULLO, Gabriel. Além da transitologia e da consolidologia: um estudo da democracia argentina realmente existente. 2005. 343f. Tese (Doutorado em Ciência Política) - Universidade Federal do Rio Grade do Sul, Porto Alegre, [2005].

REVISTA DEBATES, Porto Alegre, v. 2, n. 2, p. 70-102, jul.-dez. 2008. 102 